\title{
Effect of the stress state on the adhesive strength of an epoxy- bonded assembly
}

\author{
Sergey Smirnov, Dmitry Konovalov, Irina Veretennikova \\ Institute of Engineering Science UB RAS, Ekaterinburg, Russia \\ smirnov.sergy@bk.ru, bttp://orcid.org/0000-0002-2083-5377 \\ satterkein@yandex.ru,bttp://orcid.org/0000-0002-5306-7765 \\ stpxia@gmail.com, bttp://orcid.org/0000-0002-8371-7546 \\ Aleksander Pestov, Viktoria Osipova \\ I. Ya. Postousky Institute of Organic Synthesis UB RAS, Ekaterinburg, Russia \\ pestov@ios.uran.ru, bttp://orcid.org/0000-0002-4270-3041 \\ osipova.sva@gmail.com, http:/ /orcid.org/0000-0001-7451-9428
}

\begin{abstract}
The paper studies the adhesive strength of aluminum alloy specimens bonded with the use of an epoxy adhesive, under the tensile-shear stress state, depending on the testing temperature. Tension of modified Arcan specimens with load angles of $0,22.5,45,67.5$, and $90^{\circ}$ with respect to the plane of adhesion is chosen as the experimental method. Experiments were performed at temperatures of $-50,+23$, and $+50{ }^{\circ} \mathrm{C}$. The analysis of the obtained results yields a linear fracture criterion and a fracture locus for the adhesive failure strain energy density, which takes into account the ratio of the elastic properties of the adhesive to those of the substrate. The region bounded by the fracture loci of adhesive strength and ultimate strain energy density determines the conditions for the safe loading of the bonded assembly in terms of the energy and force criteria of adhesive failure. The proposed fracture loci can be used, preferably simultaneously, to estimate the in-service strength and reliability of adhesively bonded assemblies.
\end{abstract}

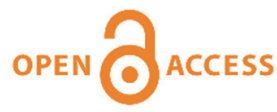

Citation: Smirnov, S., Konovalov, D. Veretennikova, I., Pestov A., Osipova, V., Effect of the stress state on the adhesive strength of an epoxy-bonded assembly, Frattura ed Integrità Strutturale, 59 (2022) $311-325$.

Received: 08.08.2021

Accepted: 08.10.2021

Published: 01.01.2022

Copyright: (C) 2020 This is an open access article under the terms of the CC-BY 4.0, which permits unrestricted use, distribution, and reproduction in any medium, provided the original author and source are credited.

KEYWORDS. Polymer coating; Stress state; Arcan specimens; Fracture criterion; Adhesives.

\section{INTRODUCTION}

$\mathrm{I}$ $\mathrm{n}$ designing advanced machinery and predicting its further development there is a consistent trend of increasing external mechanical, thermal and other loads and maintaining performance and durability under extreme operating conditions, including emergency situations. This clearly manifests itself in the development of aerospace equipment, 
structures and devices to be operated in the Arctic. For example, thermal stresses resulting from a great difference between the temperatures on the sunny and shady sides of structures in the regions of the Far North and Antarctica cause cyclic thermal strains. This may significantly damage protective coatings and adhesively bonded assemblies, the material of which is subjected to additional loads due to the different thermal expansion coefficients of the coating and the metal base. Construction, snow, and wind loads on structures induce a complex stress state in protective coatings and bonded assemblies, which is aggravated by the effect of negative temperatures. As a rule, in the engineering specifications for adhesive materials there is information only on ultimate shear strength (less frequently on cleavage strength) and mostly at room temperature. This prevents making adequate design calculations of the strength of coatings and adhesively bonded assemblies in operating structures and mechanisms, particularly with the use of advanced CAD/CAE systems.

The current world trend and potential practical requirements are met by models of cohesive and adhesive failure of bonded assemblies and coatings that take into account the effect of the stress state on failure; these models can be used as a basis for an approach to evaluating the sufficiency of the strength properties of coatings and adhesive joints. In engineering practice, an assumption is widely accepted that adhesive failure occurs as soon as certain criteria are met which are some limiting values of a combination of stresses acting in the plane of the joint [1-2]. Generally, these stresses are normal and tangential. This approach organically takes into account the effect of the values and signs of the acting stresses, as well as their ratios, on adhesive failure. A number of the most widely used criteria for modeling failure under complex stress conditions can be highlighted [3-6]. Nevertheless, the application of these criteria to the prediction of adhesive failure has a number of constraints, which are as follows: they cannot be used when there are stress singularities; the effect of adhesive layer thickness can hardly be reproduced correctly [7]; the stress-strain history of the material being loaded is not taken into account.

In mechanics, one of the most fruitful ideas for describing the failure of glued boundaries is the idea of introducing an interlayer having the same mechanical properties as the adhesive or different from them [8-11]. This enables one to use the known continual models of strength or to create new specific models of media, taking into account the effect of interface discontinuities on the strength of the assembly. When linear mechanics models describing fracture under elastic stresses are used, the values of the critical cleavage and shear stress intensity factors $\kappa_{\text {Ic }}$ and $\kappa_{\text {IIc }}$, respectively, are determined experimentally; for other types of the stress state the fracture criterion is composed of various combinations including $\kappa_{\mathrm{Ic}}$ and $\kappa_{\text {IIc }}$. Despite substantial constraints (applicability to assemblies with low adhesive strength, assumptions on the presence of significantly large defects, etc.), publications on studies using this approach are fairly numerous in the current scientific and technical literature on adhesion. For example, [12] and [13] are noteworthy among the latest publications. The criteria of nonlinear failure mechanics have found no application since it is necessary to take into account the crack opening angle, which is a priori unknown [14].

The approach using the strain energy release rate $G_{c}$ to characterize adhesive failure is widespread $[15,16]$. (The strain energy release rate $G_{c}$ is defined as a decrease in the total elastic energy in the specimen per unit specimen width with an infinitesimal increase in the delamination length.) It was experimentally found that the ultimate values of $\mathrm{G}_{\mathrm{c}}$ at fracture are different for cleavage and shear $\left(G_{I c}\right.$ and $G_{I I c}$, respecrively); therefore, to predict the values of $G_{c}$ for mixed loading conditions, when the normal $\sigma_{\mathrm{n}}$ and tangential $\sigma_{\mathrm{t}}$ stresses act simultaneously, J. Hutchinson and Z. Suo [17] proposed to consider $G_{c}$ as dependent on the phase angle $\psi=\operatorname{arctg}\left(\sigma_{t} / \sigma_{n}\right)$. According to ASTM D5528, the values of $G_{\text {Ic }}$ and $G_{\text {IIc }}$ for an adhesive joint are determined at the corresponding fixed stress state arising at the start of the displacement of a previously arrested crack or the tip of an artificially applied glue line defect. The value of energy release rate characterizes the ability to resist spontaneous delamination crack propagation along the interface under the action of external loads, and it conceptually characterizes the survivability of the joint in the presence of discontinuities on the interface. The presence and sizes of defects on interfaces are a priori unknown, and this decreases the applicability of this parameter to engineering developments. Therefore, for the design estimate of the adhesive strength of a bonded assembly, it is important to have phenomenological fracture criteria describing the conditions for the initial discontinuity of the joint.

The ultimate stress state, at which the adhesive joint fractures, is an important force characteristic to be considered when designing adhesively bonded assemblies. The work required to break an adhesive joint characterizes the energy consumption of the fracture process, and it is also an important parameter to determine operational safety [18-20]. With a sufficient level of energy consumption, upon reaching the ultimate load, an adhesive assembly will preserve its bearing capacity for some time due to deformation (viscous-elastic-plastic in the general case) appearing in the assembly materials. Therefore, for prediction purposes, it is necessary to know the energy and load bearing limits of an adhesive joint. The tension+shear loading pattern is fairly widespread in practice and the most dangerous for the structural integrity of an adhesive assembly, when the angle between the normal to the bond line and the resultant of forces (external and gravity) is at most $90^{\circ}$. 
The limit characteristics of adhesive assemblies are generally determined from the results of mechanical testing, which can be aimed either at the physical laboratory simulation of the behavior of specific assembly components under expected operating conditions or at obtaining empirical information for identification of failure criteria and models used in design and verification calculations. The latter aim can be effectively achieved by using modification of Arcan specimens [21-31], which enable the cleavage stress to shear stress ratio to be varied in a wide range. The test results can offer fracture loci determining the limit states of adhesive assemblies as dependent on the stress state and thermomechanical loading conditions [30-32]. However, it is noted herewith that, in order to obtain correct results, it is necessary to decrease or take into account the effect of stress concentration at the specimen edges [25-28].

The aim of this paper is to study the temperature dependence of the adhesive strength of epoxy-bonded aluminum alloy specimens under the tension+shear stress state and to describe the obtained experimental results with the use of criteria applicable to predicting the probability of the failure of the assembly under operating conditions.

\section{MATERIAL AND METHODS}

he adhesive strength of specimens made of the 1570 aluminum-magnesium-lithium alloy containing $5.18 \% \mathrm{Mg}$, $0.23 \% \mathrm{Sc}$, and $0.07 \% \mathrm{Zr}$ was studied. This alloy is used in aerospace industry for making structural components. Epoxy resin (bisphenol A diglycidyl ether) with 21.1\% epoxy groups (Sverdlov Plant, FSE, Russia), cured with polyethylene polyamine $(36.16 \% \mathrm{~N}$ content and $232 \mathrm{~g} / \mathrm{mol}$ molecular weight) was used to bond the specimens. To study the effect of the stress state on adhesive strength, we used modified Arcan specimens [22] with inserts from bonded specimen halves (Fig. 1).

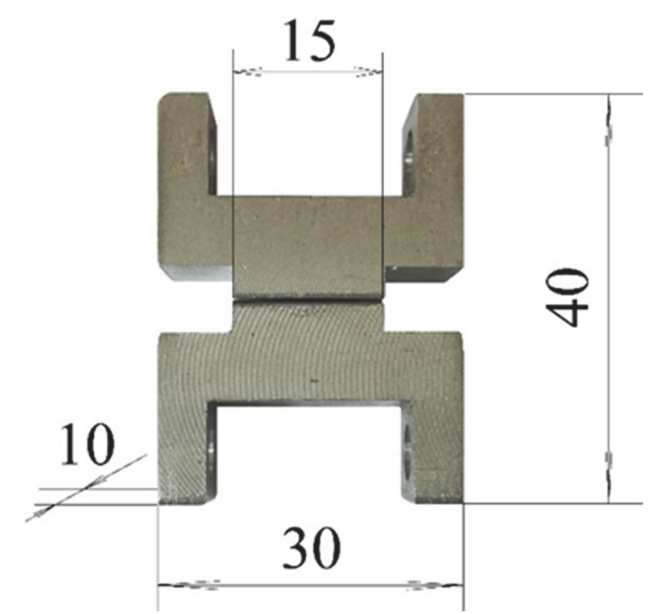

Figure 1: General view of the specimen (dimensions in $\mathrm{mm}$ )

The specimens were made from a 32-mm hot-rolled plate. The specimen surface was first machined by milling in order to obtain the required roughness and to remove the oxide film. The roughness $\mathrm{Ra} 0.4 \mu \mathrm{m}$ on the plate contact surfaces after machining and abrasion was determined by an NT 1100 non-contact profilograph/profilometer (Fig. 2).

The Epoxy resin was mixed with the hardener in a ratio of 10:1 and applied onto the degreased surfaces of the specimen halves, which were then joined together and left for 24-hour polymerization at room temperature. The adhesive layer thickness was $0.2 \pm 0.02 \mathrm{~mm}$. The testing was performed in a Zwick/Roell Z2.5 universal testing machine equipped with a KTKh-20 environmental chamber enabling testing to be performed at temperatures ranging between -80 and $+180{ }^{\circ} \mathrm{C}$.

For calculations, the necessary values of the normal elastic modulus of the adhesive material at the test temperatures were determined from the results of dynamic mechanical analysis with the use of a DMA Eplexor 100 N. Specimens with a diameter of $4 \mathrm{~mm}$ and a height of $6 \mathrm{~mm}$ were made by molding and hardened for 24 hours at room temperature. The following test parameters were used: compression as the loading type, a static load of $100 \mathrm{~N}$, a dynamic load of $5 \mathrm{~N}$ at a frequency of $10 \mathrm{~Hz}$, a temperature variation of -60 to $+95^{\circ} \mathrm{C}$ at a rate of 1 degree per minute. The specimens were cooled in the test chamber of the device in liquid nitrogen vapors and heated by the heating elements placed in the test chamber. The heating/cooling temperature conditions were controlled automatically by the actuating systems of the device. The force and displacement parameters as functions of the testing time were recorded into the built-in controller 


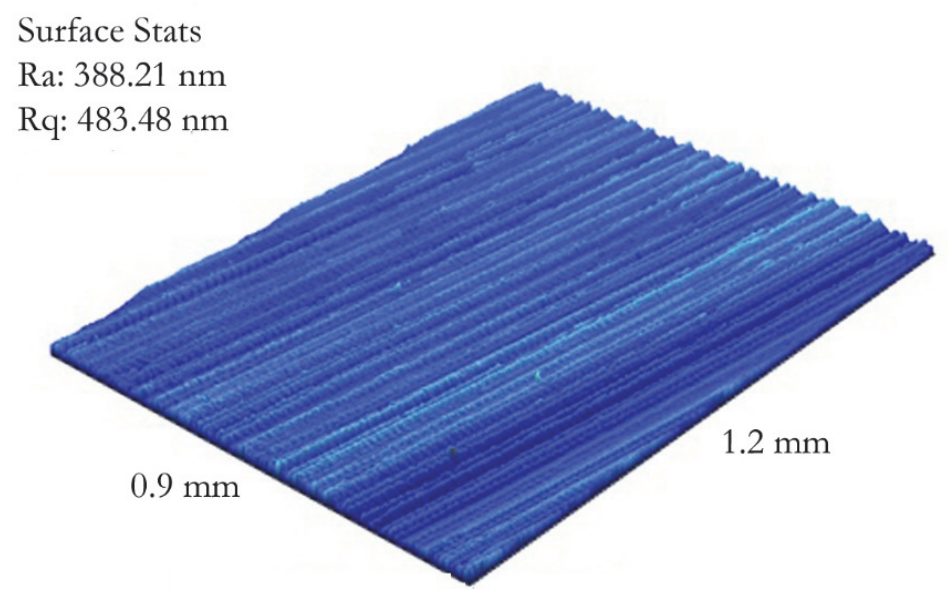

Figure 2: A 3D profile of the contact surface of the 1570 alloy insert and the measured roughness characteristics

of the device, and they were used to calculate the dynamic elastic modulus $E^{*}$ represented in the form of a complex operator as

$$
E^{*}=E^{\prime}+i E^{\prime \prime},
$$

where $E^{\prime}=E^{*} \cos \delta$ is the storage modulus, $E^{\prime \prime}=E^{*} \sin \delta$ is the loss modulus, $E^{*}=\sqrt{\left(E^{\prime}\right)^{2}+\left(E^{\prime \prime}\right)^{2}}, \delta$ is the lag angle (the loss angle) between the changes of strain and stress under sinusoidal loading conditions, $E^{*}=\Delta \sigma / \Delta \varepsilon, \Delta \sigma$ and $\Delta \varepsilon$ are the stress and strain ranges in a loading cycle.

The real part of the complex operator (1) characterizes the elastic properties of the material, and the imaginary part characterizes the viscous properties. The higher the value of $\tan (\delta)=E^{\prime \prime} / E^{\prime}$, the more pronounced are the viscous properties of the material.

The authors of [32] et al. studied the effect of the shape of Arcan specimen edges on the inhomogeneity of the stress state at the interface between the adhesive and the specimen and proposed to make the specimen edges beak-shaped [29].

Such specimens are rather difficult to make; therefore, we used specimens bonded so that the profile of the lateral surface had a mushroom shape. The profile was formed by using a special mold to remove excess adhesive squeezed out of the interface between the insert halves to be bonded. The profilogram of a portion of the adhesive ridge, which was obtained by non-contact scanning with the NT 1100 profilograph/profilometer, is shown in Fig. 3a. The ridge thickness was equal to an adhesive layer thickness of $0.2 \mathrm{~mm}$, and the average width was about $0.3 \mathrm{~mm}$. In order to assess the effect this shape of the lateral surface of the adhesive layer has on the distribution of contact stresses, tensile and shear testing was simulated with the use of the ANSYS v.16.2 software package. The calculation was made in the Shared Access Center of the Institute of Mathematics and Mechanics, UB RAS. For comparison, testing of specimens with a flat shape of the adhesive layer was simulated. The problems were solved in the elastic statement under plane stress conditions. The ridge thickness and width values were assumed equal to the average values obtained from the measurements of the ridge profile ( 0.2 and $0.3 \mathrm{~mm}$, respectively). The spherical radius was conventionally assumed to be $0.15 \mathrm{~mm}$ since, according to the measurement results, the rounding portion had a complex and variable shape, which is difficult to describe analytically. The values of the elastic modulus $E^{*}$ and its components are presented in Tab. 1, wherefrom it follows that the value of the loss tangent $\tan (\delta)$ is small; therefore, the adhesive material can be simulated by an elastic medium. Similar assumptions were made for the material of the metallic specimens. Quasi-static loading is considered, the heat and inertial effects being negligible. The contact pair was not specified on the interface. The model parts belonging to the adhesive and the specimens had nodes in common on the interface. In the simulation of shear, the following boundary conditions were specified (Fig. 4): displacements $u_{\mathrm{x}}=u_{\mathrm{y}}=0$ (surface A2), $u_{\mathrm{x}}=0$ (surface A1); pressure $p=p^{*}$ (line L1). In the simulation of cleavage, the boundary conditions were specified as follows: displacements $u_{\mathrm{x}}=u_{\mathrm{y}}=0$ (surface A2), $u_{\mathrm{x}}=0$ (line L4); pressure $\mathrm{p}=\mathrm{p}^{* *}$ (line L2). Here, $p^{*}$ and $p^{* *}$ are the pressures specified by the problem conditions.

PLANE 183 finite elements with refinement near the specimen edges were used for constructing the computational grid. A series of computational experiments was performed with varying the shape of the lateral surface of the adhesive layer, e.g. convex, concave, etc. The effect of the geometric dimensions of the specimens was not discussed since, with the design of the testing equipment used in the study, the possibility to vary these dimensions was limited. As a result, the 
lateral surface was chosen in the form of a small mushroom-shaped adhesive ridge with a thickness equal to that of the adhesive layer. Fig. 3a shows the finite-element grid near the specimen edge with a ridge, the simulation results being shown in Fig. 3c,d,e,f. It follows from the data that, when a mushroom-shaped ridge is formed at the specimen edges, a favorable stress state appears at the interface near the specimen edges as distinct from that of the specimens with a flat lateral surface of the adhesive layer. Namely, in cleavage testing, the tensile stresses decrease rather than increase; in shear testing, the normal tensile stresses decrease by more than a factor of 7 . As distinct from the case of the specimens with a flat lateral surface of the adhesive layer, this makes the appearance of delamination cracks hardly probable. Due to a small thickness of the adhesive ridge, its presence insignificantly affects the tensile force.

(a)

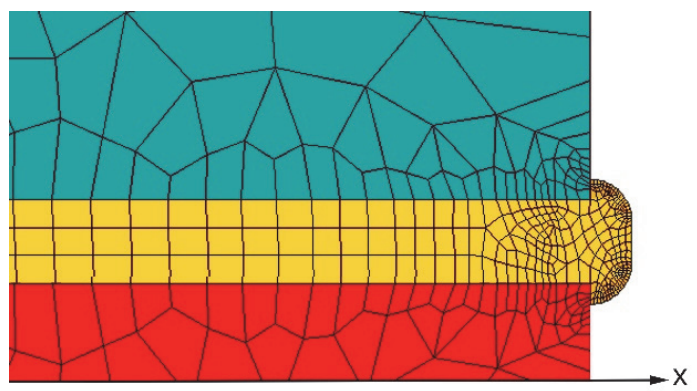

(c)

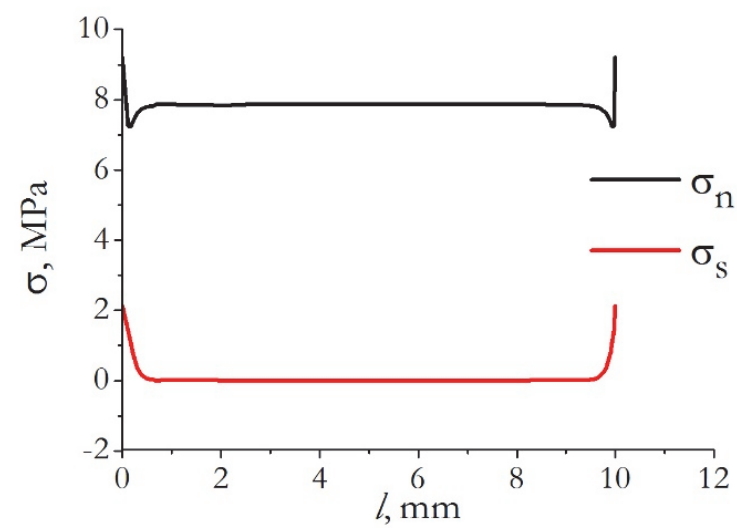

(e)

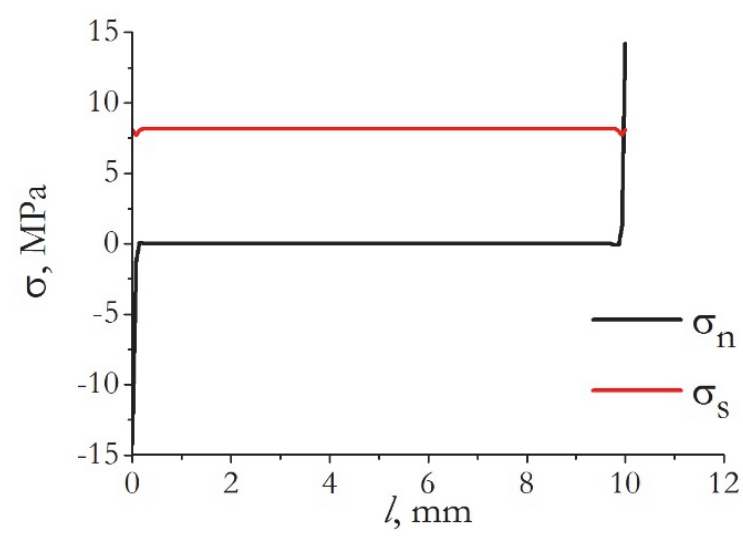

(b)

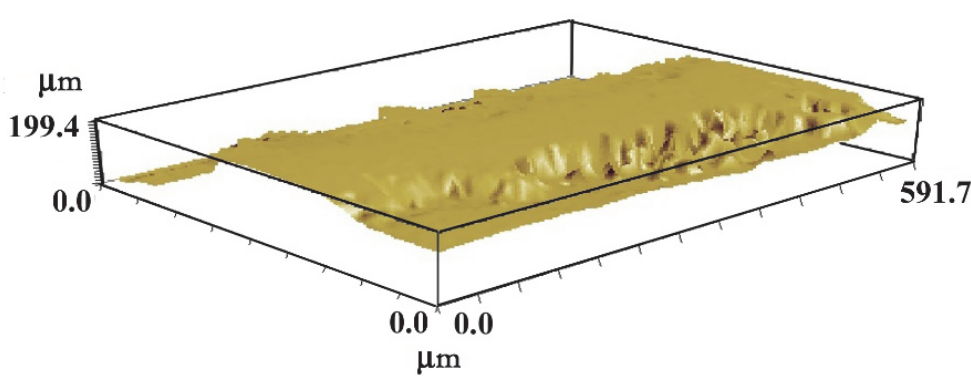

(d)

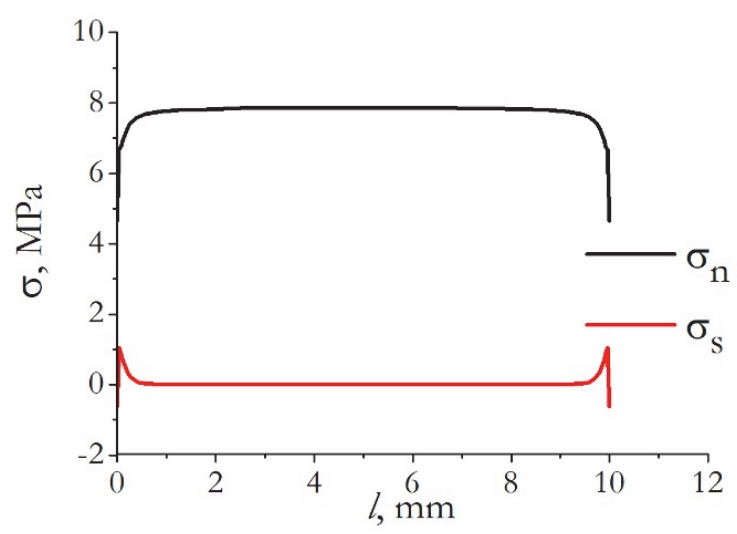

(f)

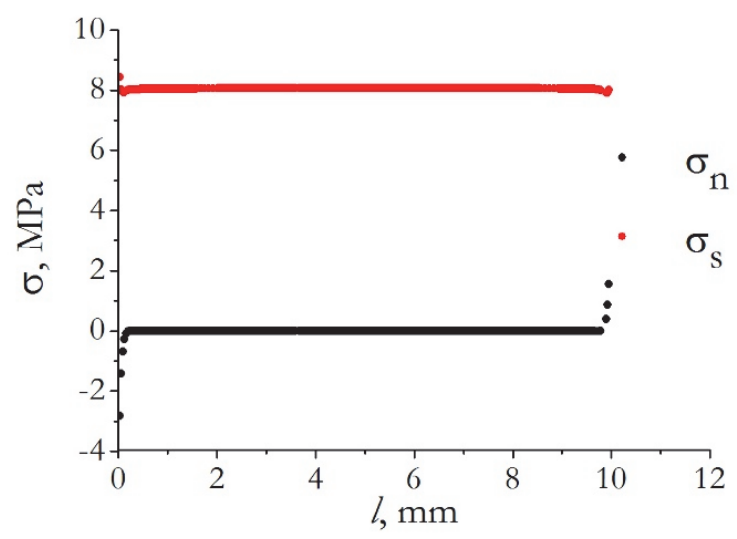

Figure 3: Finite-element model of a specimen with an adhesive ridge on its lateral surface (a); profilogram of the adhesive ridge on the specimen (b); results of the simulation of the stress state for the flat lateral surface of the adhesive layer (c, e) and the presence of a mushroom-shaped ridge $(d, f)$ in cleavage testing $(c, d)$ and shear testing $(e, f)$. 
The modified Arcan specimens were fixed in the machine grips so that the angle $\alpha$ between the tension direction and the normal to the joint plane was $0,22.5,45,67.5$, and $90^{\circ}$ (Fig. 5). Separation under the action of normal tensile stresses was implemented at $\alpha=0$, the shear stress state caused by the action of tangential stresses was implemented at $\alpha=90^{\circ}$, and a complex tension + shear stress state was implemented at intermediate values of $\alpha$.

The testing was performed at $-50,+23$, and $+50{ }^{\circ} \mathrm{C}$. The specimens were placed in the environmental chamber of the testing machine, fixed in the grips, and held for 15 min until reaching the temperature of the environmental chamber. A preload of $50 \mathrm{~N}$ was applied in order to eliminate clearances in the joining parts of the testing machine. The specimens were then tensioned at a rate of $1 \mathrm{~mm} / \mathrm{min}$ to failure. The force $P$ and the relative displacement $\Delta_{\mathrm{y}}$ of the specimen halves along the loading direction during the testing were varied by a dynamometer and an extensometer complementing the testing machine.

After testing, in order to identify the failure pattern, the specimen surface was examined with a binocular microscope and the NT 1100 non-contact profilograph/profilometer.

\begin{tabular}{cccc}
\hline$T,{ }^{\circ} \mathrm{C}$ & -50 & +23 & +50 \\
$E^{\prime}(\mathrm{MPa})$ & 5230 & 4530 & 4220 \\
$E^{\prime \prime}(\mathrm{MPa})$ & 41 & 91 & 163 \\
$E^{*}(\mathrm{MPa})$ & 5239 & 4518 & 4211 \\
$\tan \delta$ & 0.009 & 0.021 & 0.031 \\
\hline
\end{tabular}

Table 1: The values of the components of the complex elastic modulus for the adhesive.

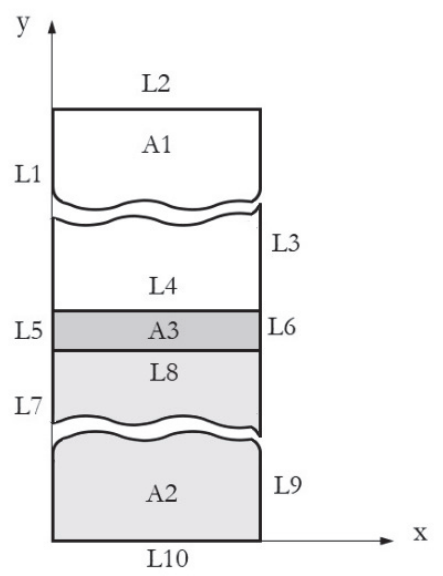

Figure 4: To the determination of boundary conditions.

\section{RESULTS AND ANALYSIS}

$\mathrm{I}$ $\mathrm{t}$ follows from the results of the finite-element analysis that the chosen shape of the lateral surface of the adhesive layer significantly impedes the formation and propagation of end cracks at the interface. The stress state is homogeneous through more than $95 \%$ of the interface length; therefore, to evaluate the stress state at fracture, the average values of normal $\sigma_{\mathrm{n}}$ and shear $\sigma_{\mathrm{s}}$ stresses can be used,

$$
\sigma_{\mathrm{n}}=\mathrm{P} / \mathrm{S} \cos (\alpha), \quad \sigma_{\mathrm{s}}=\mathrm{P} / \mathrm{S} \sin (\alpha)
$$

where $P$ is the ultimate tensile force recorded by the force-measuring gauge of the testing machine at the fracture of the adhesive joint; $S=150 \mathrm{~mm}^{2}$ is the bond area. 
(a)

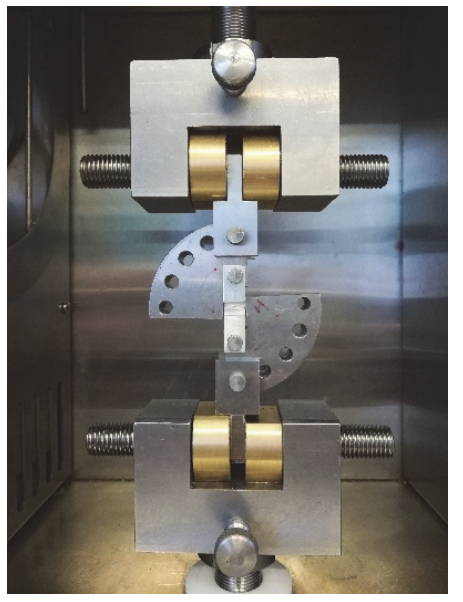

(d) (b)

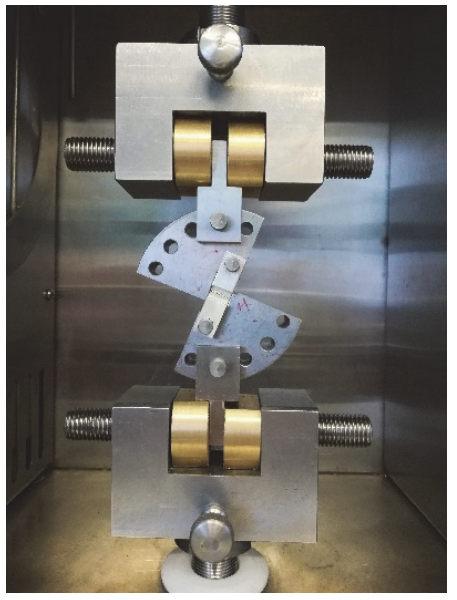

(c)

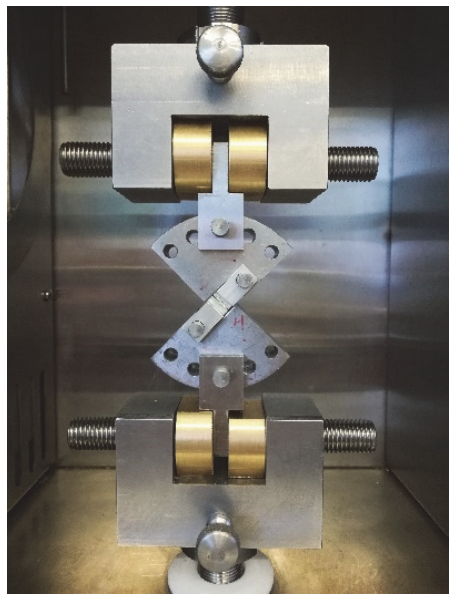

(e)
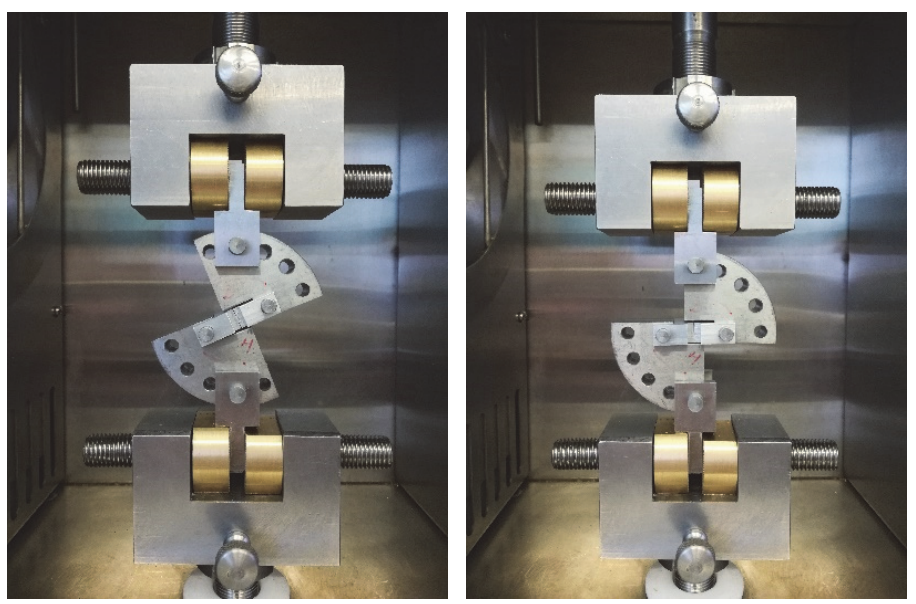

Figure 5: Modified Arcan specimens used to determine adhesive strength under tension with shear; the angle $\alpha$ between the tensile axis and the joint plane: 0 (a); $22.5^{\circ}$ (b); $45^{\circ}$ (c); $67.5^{\circ}$ (d); $90^{\circ}$ (e)

The loading diagrams are straight lines, and this enables us to consider that the fracture occurs within the elastic strain of the adhesive layer.

When formulating the local fracture criterion, we used the assumption that the value of strain energy density in a selected microvolume including the interface is the driving force for the delamination of the adhesive joint under the force action. To do this, we arbitrarily select a microvolume at the interface, which simultaneously belongs to the adhesive and the substrate (the aluminum insert) and contains the interface inside, along which slip and delamination are prohibited (Fig. 6). The microvolume is in the equilibrium at the moment, and on its opposite faces there are equal stresses $\sigma_{\mathrm{ij}}$ in the local coordinate system $\left(x^{\prime}, y^{\prime}, z^{\prime}\right)$. The $z^{\prime}$-axis is directed along the normal to the interface, and the $x^{\prime}$-and $y^{\prime}$-axes lie in its plane. The stresses $\sigma_{\mathrm{ij}}$ are calculated by solving the problem of stress-strain state determination. The effective values of the components of elastic strain $\varepsilon_{\mathrm{ij}}$ in the microvolume can be found from the physical equations

$$
\sigma_{\mathrm{ij}}-\sigma \delta_{\mathrm{ij}}=2 \mathrm{G}\left(\varepsilon_{\mathrm{ij}}-\frac{1}{3} \varepsilon \delta_{\mathrm{ij}}\right) \text {, }
$$

where $\sigma=\varepsilon / 3 \mathrm{k}$ is hydrostatic stress, $G=\mathrm{E} /(2(1+v)), v$ is the Poisson ratio, $\varepsilon=\varepsilon_{\mathrm{ii}}$ is volumetric strain, $k=(1-2 /$ is the bulk compression modulus, $\delta_{\mathrm{ij}}$ is the Kronecker delta $(\delta=1$ when $i=j, \delta=0$ when $i \neq j)$. 


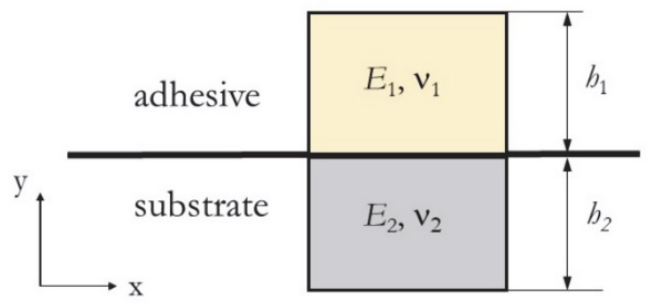

Figure 6. Selected microvolume

To determine the effective values of the normal elastic modulus $\overline{\mathrm{E}}$, the shear modulus $\overline{\mathrm{G}}$, and the Poisson ratio $\bar{v}$ for the selected microvolume under plane stress conditions, we can use the following formulas found in $[33,34]$ :

$$
\frac{\mathrm{h}}{\overline{\mathrm{E}}}=\frac{\mathrm{h}_{1}}{\mathrm{E}_{1}}+\frac{\mathrm{h}_{2}}{\mathrm{E}_{2}} ; \quad \bar{v}=\frac{v_{1} \mathrm{~h}_{1} \mathrm{E}_{2}+v_{2} \mathrm{~h}_{2} \mathrm{E}_{1}}{\mathrm{~h}_{1} \mathrm{E}_{2}+\mathrm{h}_{2} \mathrm{E}_{1}} ; \frac{\mathrm{h}}{\overline{\mathrm{G}}}=\frac{\mathrm{h}_{1}}{\mathrm{G}_{1}}+\frac{\mathrm{h}_{2}}{\mathrm{G}_{2}},
$$

where $h_{1}, h_{2}$ are the adhesive and substrate layer thicknesses in the selected microvolume; $E_{1}, v_{1}, G_{1}$ and $E_{2}, v_{2}, G_{2}$ are the values of the normal elastic modulus, the Poisson ratio, and the shear modulus of the adhesive and substrate materials, respectively.

The ratio between the values of the layer thicknesses $h_{1}$ and $h_{2}$ in the selected microvolume is here considered to be inversely proportional to the values of the normal elastic moduli of the adhesive and the substrate according to the following equation:

$$
\mathrm{h}_{1}=\mathrm{h}_{2} \frac{\mathrm{E}_{2}}{\mathrm{E}_{1}} .
$$

Substituting Eq. (4) into Eq. (3), after simple transformations, we obtain the following formulas to calculate the effective values of $\overline{\mathrm{E}}, \overline{\mathrm{G}}$, and $\bar{v}$ for the selected microvolume:

$$
\overline{\mathrm{E}}=\frac{\mathrm{E}_{1}+\mathrm{E}_{2}}{\frac{\mathrm{E}_{1}}{\mathrm{E}_{2}}+\frac{\mathrm{E}_{2}}{\mathrm{E}_{1}}} ; \bar{v}=\frac{v_{1} \mathrm{E}_{2}^{2}+v_{2} \mathrm{E}_{1}^{2}}{\mathrm{E}_{1}^{2}+\mathrm{E}_{2}^{2}} ; \overline{\mathrm{G}}=\frac{\mathrm{G}_{1}+\mathrm{G}_{2}}{\frac{\mathrm{G}_{1}}{\mathrm{G}_{2}}+\frac{\mathrm{G}_{2}}{\mathrm{G}_{1}}}
$$

(a)

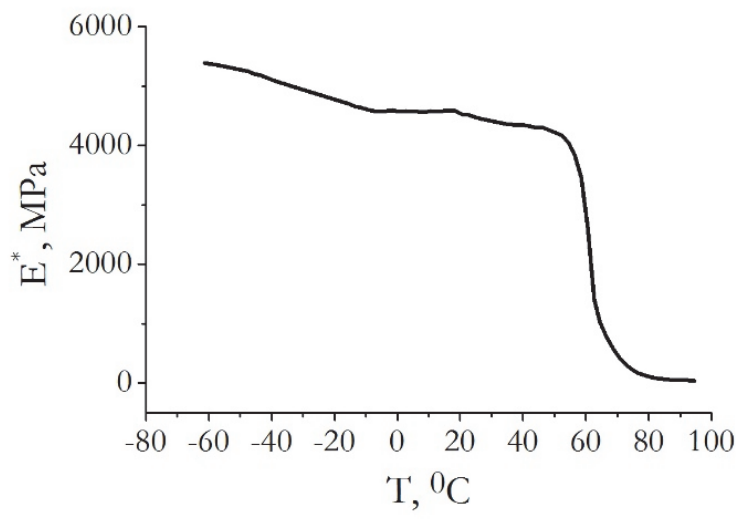

(b)

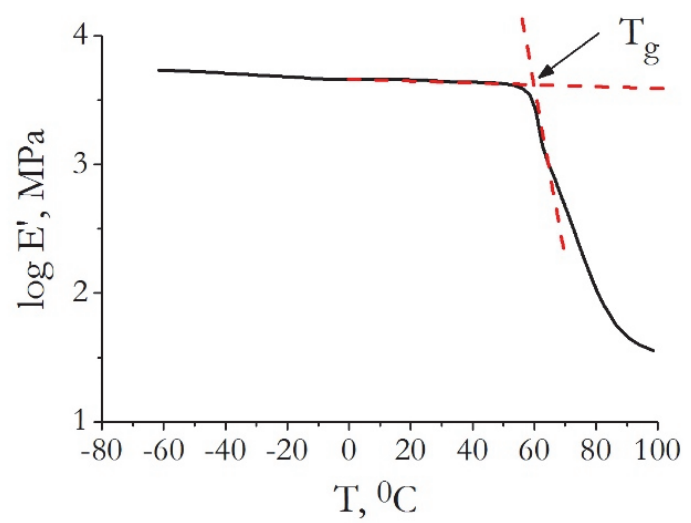

Figure 7: The effect of temperature on the behavior of the elastic modulus.

Determined by dynamic mechanical analysis, the temperature dependence of the normal elastic modulus of the adhesive material is shown in Fig. $7 \mathrm{a}$. The glass transition temperature $T_{\mathrm{g}}=68{ }^{\circ} \mathrm{C}$ was determined according to ASTM D7028 at 
the points of intersection of the tangents to the lines showing the dependences of $\log E^{\prime}$ on the testing temperature $T$ before and after the inflection point (Fig. 7b). Thus, at the testing temperatures, the adhesive material was in the crystalline state.

Taking this into account, when calculating by Eq. (5), we assume the following values of the elastic constants: from Tab. 1, depending on the testing temperature, $E_{1}=E^{*}, v_{1}=0.35$ for the adhesive [35]; $E_{2}=69.58 \mathrm{GPa}, v_{2}=0.27 \mathrm{for}$ the 1570 alloy substrate [36].

It follows from Tab. 2 that the values of the effective elastic moduli for the selected microvolume exceed those for the adhesive material by 5 to $7 \%$. The value of the effective Poisson ratio is practically the same as its value for the adhesive material.

\begin{tabular}{|c|c|c|c|c|c|c|}
\hline$T,{ }^{\circ} \mathrm{C}$ & $\bar{E}, \mathrm{GPa}$ & $\frac{\bar{E}-E}{E} 100 \%$ & $\bar{G}, \mathrm{GPa}$ & $\frac{\bar{G}-G}{G} 100 \%$ & $\bar{v}$ & $\frac{\bar{v}-v}{v} 100 \%$ \\
\hline-50 & 5603 & 6.9 & 2084 & 6.6 & 0.349 & -0.1 \\
\hline 23 & 4793 & 6.0 & 1783 & 5.6 & 0.349 & -0.1 \\
\hline 50 & 4448 & 5.6 & 1656 & 5.3 & 0.350 & $<-0.1$ \\
\hline
\end{tabular}

Table 2: The effective characteristics of the elastic properties of the selected microvolume.

The values of the strain energy density components $W_{\mathrm{n}}$ and $W_{\mathrm{s}}$ in the selected microvolume are calculated by the formulas

$$
\mathrm{W}_{\mathrm{n}}=\frac{\sigma_{\mathrm{n}}^{2}}{2 \overline{\mathrm{E}}} ; \mathrm{W}_{\mathrm{s}}=\frac{\sigma_{\mathrm{s}}^{2}}{2 \overline{\mathrm{G}}}
$$

Tab. 3 shows the experimental values of the specimen failure load $P_{\max }$ averaged from the results of testing 3 to 5 specimens for each combination of temperature and the angle $\alpha$. It also demonstrates the values of $\sigma_{\mathrm{n}}, \sigma_{\mathrm{s}}, W_{\mathrm{n}}$, and $W_{\mathrm{s}}$, calculated for the averaged values of $P_{\max }$, some graphic interpretations of the data from Tab. 3 being shown in Figs. 8 and 9 .

Tab. 4 shows the ultimate values of strain energy density $W_{\mathrm{n}}^{*}$ for pure cleavage $(\alpha=0)$ and $W_{\mathrm{s}}^{*}$ for pure shear $\left(\alpha=90^{\circ}\right)$ determined for various testing temperatures. The values of $W_{\mathrm{n}}^{*}$ and $W_{\mathrm{s}}^{*}$ were calculated by Eq. (6) for the averaged mean values of $\sigma_{\mathrm{n}}$ and $\sigma_{\mathrm{s}}$ from Tab. 3 .

It follows from Tab. 4 that, when $T=23$ and $50{ }^{\circ} \mathrm{C}$, the values of ultimate strain energy density in cleavage and shear $W_{\mathrm{n}}^{*}$ and $W_{\mathrm{s}}^{*}$ are approximately equal, but $W_{\mathrm{s}}^{*}>W_{\mathrm{n}}^{*}$ when $T=-50{ }^{\circ} \mathrm{C}$.

Under the complex stress state, when cleavage and shear stresses act simultaneously, the correlation of the values of $W_{\mathrm{n}}^{*}$ and $W_{\mathrm{s}}^{*}$ at adhesive failure are described by straight lines in Fig. 8.

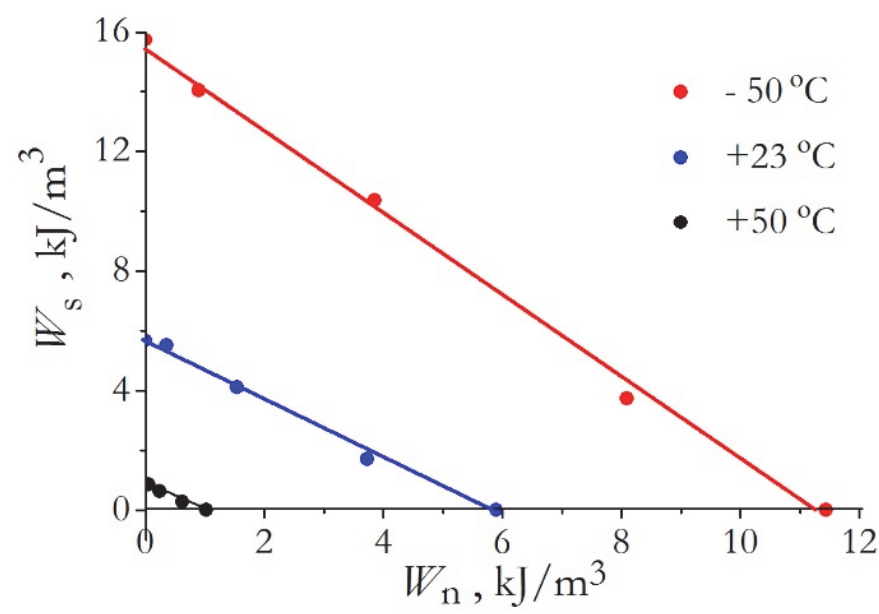

Figure 8: The diagrams of ultimate strain energy density at adhesive failure. 


\begin{tabular}{|c|c|c|c|c|c|c|}
\hline$T,{ }^{\circ} \mathrm{C}$ & $\alpha,{ }^{\circ}$ & $P_{\max }, \mathrm{N}$ & $\sigma_{\mathrm{n}}, \mathrm{MPa}$ & $\sigma_{\mathrm{s}}, \mathrm{MPa}$ & $W_{\mathrm{n}}, \mathrm{kJ} / \mathrm{m}^{3}$ & $W_{\mathrm{s}}, \mathrm{kJ} / \mathrm{m}^{3}$ \\
\hline \multirow[t]{5}{*}{-50} & 90 & 1215 & 0 & 8.10 & 0 & 15.74 \\
\hline & 67.5 & 1242 & 3.17 & 7.65 & 0.90 & 14.04 \\
\hline & 45 & 1394 & 6.57 & 6.57 & 3.85 & 10.36 \\
\hline & 22.5 & 1546 & 9.52 & 3.94 & 8.09 & 3.73 \\
\hline & 0 & 1698 & 11.32 & 0 & 11.44 & 0 \\
\hline \multirow[t]{5}{*}{23} & 90 & 675 & 0 & 4.50 & 0 & 5.67 \\
\hline & 67.5 & 720 & 1.84 & 4.43 & 0.35 & 5.51 \\
\hline & 45 & 812 & 3.82 & 3.82 & 1.53 & 4.11 \\
\hline & 22.5 & 970 & 5.97 & 2.47 & 3.72 & 1.72 \\
\hline & 0 & 1127 & 7.52 & 0 & 5.89 & 0 \\
\hline \multirow[t]{5}{*}{50} & 90 & 252 & 0 & 1.68 & 0 & 0.85 \\
\hline & 67.5 & 275 & 0.70 & 1.69 & 0.06 & 0.87 \\
\hline & 45 & 310 & 1.46 & 1.46 & 0.24 & 0.64 \\
\hline & 22.5 & 380 & 2.35 & 0.97 & 0.62 & 0.29 \\
\hline & 0 & 451 & 3.01 & 0 & 1.02 & 0 \\
\hline
\end{tabular}

Table 3: Experiment results.

The equations of the approximating lines in Fig. 8 can be written as

$$
\frac{\mathrm{W}_{\mathrm{n}}}{\mathrm{W}_{\mathrm{n}}^{*}}+\frac{\mathrm{W}_{\mathrm{s}}}{\mathrm{W}_{\mathrm{s}}^{*}}=1
$$

where the denominators are equal to the lengths intercepted by the straight lines intersecting the coordinate axes and equal to the values of the strain energy density components at fracture under cleavage $W_{\mathrm{n}}^{*}$ and shear $W_{\mathrm{s}}^{*}$ from Tab. 4. Eqn. (8) has the meaning of a fracture criterion under the tension+shear complex stress state for adhesive failure. In the normalized coordinates $\left(\frac{\mathrm{W}_{\mathrm{n}}}{\mathrm{W}_{\mathrm{n}}^{*}}, \frac{\mathrm{W}_{\mathrm{s}}}{\mathrm{W}_{\mathrm{s}}^{*}}\right)$, the fracture locus has a generalized form in Fig. 9. Note that the linear fracture criterion like that represented by Eq. (8) was used, e.g. in [37], to predict crack propagation conditions, but with energy release rate $G$ used instead of strain energy density.

\begin{tabular}{cccc}
\hline$T,{ }^{\circ} \mathrm{C}$ & -50 & +23 & +50 \\
$W_{\mathrm{n}}^{*}, \mathrm{~kJ} / \mathrm{m}^{3}$ & 11.44 & 5.89 & 1.02 \\
$W_{\mathrm{s}}^{*}, \mathrm{~kJ} / \mathrm{m}^{3}$ & 15.74 & 5.67 & 0.85 \\
\hline
\end{tabular}

Table 4: The ultimate values of the strain energy density components $W_{\mathrm{n}}^{*}$ and $W_{\mathrm{s}}^{*}$. 


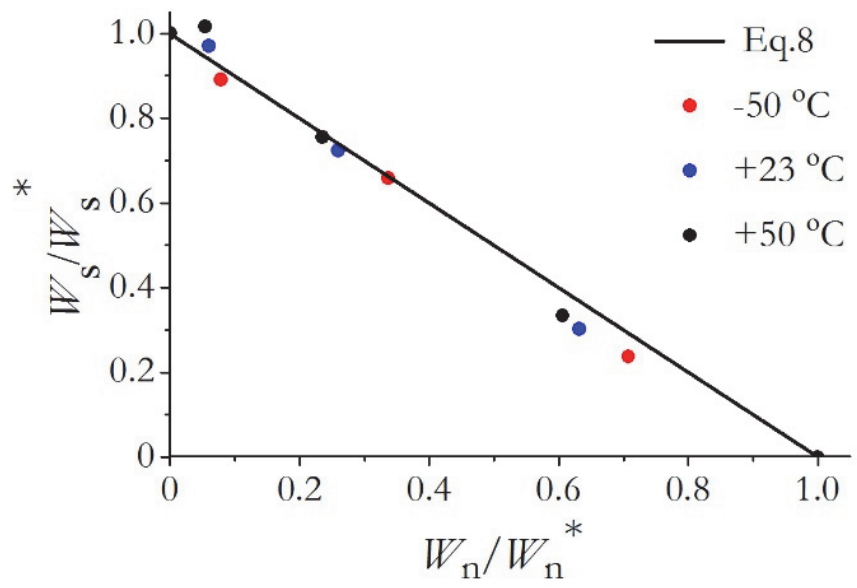

Figure 9: Graphic representation of the fracture criterion expressed by Eq. (8): the dots on the graph correspond to the experimental data.

Since under elastic loading the cleavage and shear stress components are related to the corresponding strain energy components by Eq. (2), the criterion represented by Eq. (8) can be written in the known quadratic form [38] as

$$
\frac{\left(\sigma_{\mathrm{n}}\right)^{2}}{\left(\sigma_{\mathrm{n}}^{*}\right)^{2}}+\frac{\left(\sigma_{\mathrm{s}}\right)^{2}}{\left(\sigma_{\mathrm{s}}^{*}\right)^{2}}=1
$$

where $\sigma_{\mathrm{n}}{ }^{*}, \sigma_{\mathrm{s}}{ }^{*}$ are the ultimate stresses at fracture under cleavage and shear, their values being shown in Tab. 5 . The fracture locus has the form of a circumference in the normalized coordinates $\left(\frac{\sigma_{\mathrm{n}}}{\sigma_{\mathrm{n}}^{*}}, \frac{\sigma_{\mathrm{s}}}{\sigma_{\mathrm{s}}^{*}}\right)$, which is shown in Fig. $10 \mathrm{~b}$.

The diagrams of the adhesive strength of the joint for the studied testing temperatures, which show the relations between cleavage stress and shear stress under the complex stress state at adhesive failure, are elliptic lines (Fig. 10a). It follows from the results that the adhesive joint has higher strength under cleavage than under shear in the entire range of temperatures studied.

\begin{tabular}{ccc}
\hline$T,{ }^{\circ} \mathrm{C}$ & $\sigma_{\mathrm{n}}{ }^{*}, \mathrm{MPa}$ & $\sigma_{\mathrm{s}}{ }^{*}, \mathrm{MPa}$ \\
-50 & 11.32 & 8.10 \\
23 & 7.52 & 4.50 \\
50 & 3.01 & 1.68 \\
\hline
\end{tabular}

Table 5: Fracture stresses under cleavage $\sigma_{\mathrm{n}}{ }^{*}$ and shear $\sigma_{\mathrm{s}}{ }^{*}$.

In view of the different values of the covalent chemical bond energy (800 to $1600 \mathrm{~kJ} / \mathrm{mol}$ ) and the intermolecular energy (at most $13 \mathrm{~kJ} / \mathrm{mol}$ ), the comparison of the mechanical testing results (Tabs. 3-5) with the chemical structure of the adhesive joint (Fig. 11) suggests that the main contribution to the cleavage strength is made by the covalent bonds $(\mathrm{C}-\mathrm{C}$ and $\mathrm{C}-\mathrm{O}$ ) of the Epoxy resin, whereas the shear strength is mainly provided by the covalent bonds of the Epoxy resin with the hydroxyl groups of the surfaces to be bonded (Al-O-C). Besides, the decrease in the values of both shear and cleavage strengths with the temperature increase to the glass transition temperature (Fig. 7 ) demonstrates that a great contribution to adhesive strength is made by molecular interactions. Herewith, a greater decrease in shear strength with increasing temperature as compared to cleavage strength testifies to a greater contribution of molecular interactions in the surface-adhesive interface than that in the bulk of the adhesive layer. 
Thus, the analysis of the obtained experimental data provides a chemical explanation for the influence of the composition of the metal surfaces on the strength of their adhesion to each other; this influence was previously observed and exemplified in [39, 40]. Besides, the detailed specification of anisotropy in the chemistry of adhesion by means of mechanical testing enables us to design targeted epoxy materials with a required chemical structure depending on the metal surfaces to be bonded and the conditions of mechanical loading. The regions bounded by the diagram lines in Figs. 8 and 10a determine the conditions for the safe loading of the adhesive assembly under study in terms of the energy and force fracture criteria, which can be used, preferably simultaneously, to estimate the in-service strength of an adhesive assembly under a complex stress state.

(a)

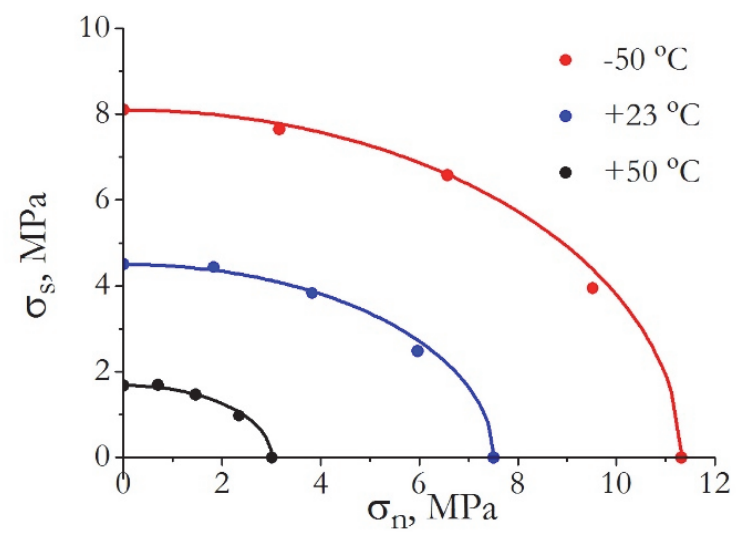

(b)

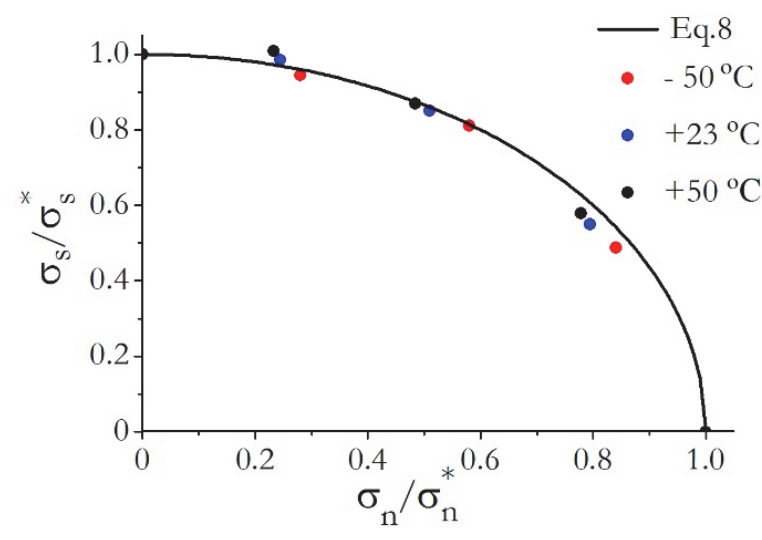

Figure 10: Adhesive strength diagrams for various testing temperatures (a) and a graphical representation of the quadratic fracture criterion in stresses under tension+shear loading for adhesive failure (b).

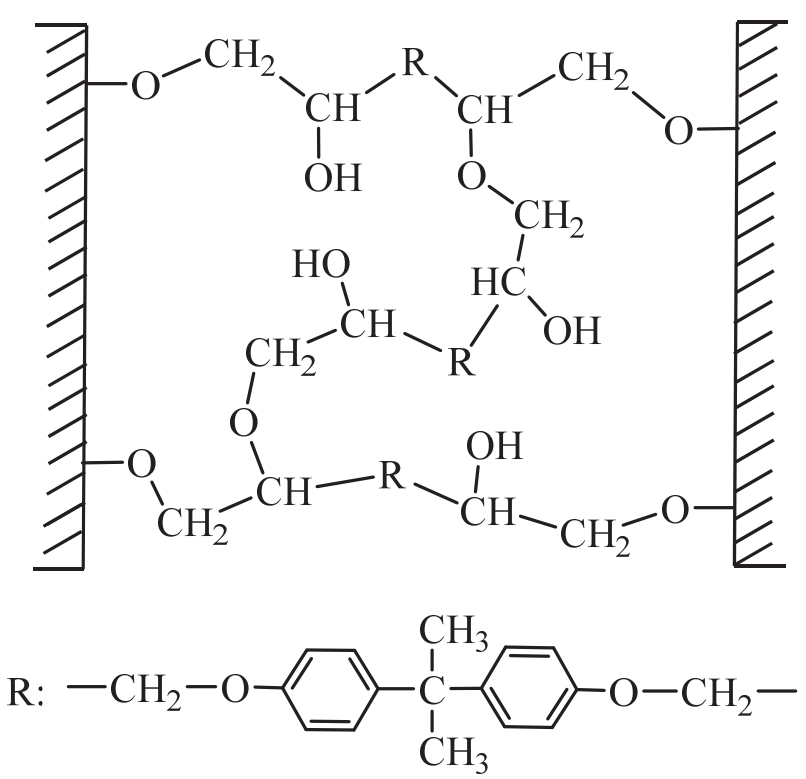

Figure 11: The basic chemical structure of cured epoxy resin (bisphenol A diglycidyl ether).

\section{CONCLUSION}

odified Arcan specimens with glued inserts have been used to study the effect of the stress state on the adhesive strength of a 1570 aluminum-magnesium-scandium alloy assembly bonded with ED-20 epoxy resin cured with polyethylene polyamine. In order to decrease stress concentration, a mushroom-shaped ridge was 
formed on the lateral surface of the adhesive layer. Finite element simulation has shown that this significantly decreases the level of normal and shear stresses near the lateral surface. This makes the appearance of edge delamination cracks hardly possible. The testing was performed at temperatures of $-50,+23$, and $+50{ }^{\circ} \mathrm{C}$ at different values of the angle between the normal to the adhesion plane and the direction of tension, i.e. from 0 (shear) to $90^{\circ}$ (cleavage). In the formulation of the fracture criterion, an assumption was used that the delamination of an adhesively bonded assembly of two bodies under a force action is driven by the value of strain energy density in a selected microvolume including the interface. The normal and shear components of strain energy density $W_{\mathrm{n}}^{*}$ and $W_{\mathrm{s}}^{*}$ at the moment of the fracture of the adhesive joint were determined with allowance made for the calculated effective properties of the selected microvolume considered as a unidirectional composite. The formulated fracture criterion takes into account the ratio of the elastic characteristics of the adhesive to those of the substrate.

It has been found that the values of the ultimate strain energy density of the adhesively bonded assembly in shear and cleavage $W_{\mathrm{n}}{ }^{*}$ and $W_{\mathrm{s}}^{*}$ are approximately equal at $T=23$ and $50{ }^{\circ} \mathrm{C}$, but $W_{\mathrm{s}}{ }^{*}>W_{\mathrm{n}}{ }^{*}$ at $T=-50{ }^{\circ} \mathrm{C}$. In the entire temperature range studied, the adhesively bonded assembly has higher strength in shear than in cleavage.

The fracture loci can be used (preferably simultaneously) for evaluating the durability and reliability of adhesive assemblies at temperatures below the glass transition temperature under the following restrictions: 1) the materials of the metallic specimens and the adhesive can be viewed as linear elastic isotropic media; 2) the failure of the adhesive assembly can be considered to have an adhesive nature; 3 ) the heat and inertial effects in the adhesive are negligible under mechanical loading.

\section{ACKNOWLEDGEMENTS}

7 he research procedure was developed according to the research plan of the IES UB RAS; the specimen preparation and the experimental study were financially supported by the Russian Scientific Foundation, grant 1919-00571. The equipment of the Plastometriya shared access center affiliated to the IES UB RAS was used for the research.

\section{REFERENCES}

[1] Smirnov, S.V., Veretennikova, I.A. and Vichuzhanin, D.I. (2014). Modeling of delamination in multilayer metals produced by explosive welding under plastic deformation, Computational Continuum Mechanics, 7(4), pp. 398-411. DOI: 10.7242/1999-6691/2014.7.4.38.

[2] Smirnov, S.V., Veretennikova, I.A., Vichuzhanin, D.I. and Pestov, A.V. (2019) Determination of the Adhesive Strength of a Laminated Glue Material under Three-Point Bending [Electronic resource], Diagnostics, Resource and Mechanics of materials and structures, 6, pp. 25-36. DOI: 10.17804/2410-9908.2019.6.025-036.

[3] Christensen, R.M. and De Teresa, S.J. (2004). Delamination Failure Investigation for out of plane Loading in Laminates, J. Comp. Mater., 38(24), pp. 2231-2238. DOI: 10.1177/0021998304046431.

[4] Christensen, R.M. (1998). The Numbers of Elastic Properties and Failure Parameters for Fiber Composites, J. Eng. Mater. Tech., 120(2), pp. 110-113. DOI: 10.1115/1.2806997.

[5] Tsai, S.W. and Wu, E.M. (1971). A General Theory of Strength for Anisotropic Materials, J. Comp. Mater., 5(Jan), pp. 58-80. DOI: 10.1177/002199837100500106.

[6] Hashin, Z. (1980). Failure Criteria for Unidirectional Fiber Composites, J. Appl. Mech., 47(2), 329-334. DOI: $10.1115 / 1.3153664$.

[7] Gleich, D.M., Van Tooren, M. J. L. and Beukers, A. (2001). Analysis and evaluation of bondline thickness effects on failure load in adhesively bonded structures, Journal of Adhesion Science and Technology, 15(9), pp. 1091-1101. DOI: $10.1163 / 156856101317035503$

[8] Xu, L. and Tippur, H.V. (1995). Fracture parameters for interface cracks: an experimental-finite element study of crack tip fields and crack initiation toughness, Int. J. Fract., 71(4), pp. 345-363.

[9] Camanho, P.P., Da'vila, C.G. and Ambur, D.R. (2001). Numerical Simulation of Delamination Growth in Composite Materials, NASA-TP-211041.

[10] Camanho, P.P., Dávila, C.G. and De Moura, M. F. (2003). Numerical Simulation of Mixed-mode Progressive Delamination in Composite Materials P. P., Journal of Composite materials, 37 (16), pp. 1415-1438.

DOI: $10.1177 / 002199803034505$. 
[11] Sung-Il Song, Kwang-Soo Kim and Hyun-Gyu Kim. (2016) Estimation of a -mode cohesive law for an interface crack between dissimilar materials, Multiscale and Multiphysics Mechanics, 1 (1), pp. 35-51. DOI: $10.12989 / \mathrm{mmm} .2016 .1 .1 .03535$

[12] Chen, D., Noda, N.-A., Takaki, R. and Sano, Y. (2020). Intensity of singular stress fields (ISSFs) in micro-bond test in comparison with ISSFs in pull-out test, International Journal of Mechanical Sciences, 183, 105817. DOI: $10.1016 /$ j.ijmecsci.2020.105817.

[13] Galvez, P., Noda, N.-A., Takaki, R., Sano, Y., Miyazaki, T., Abenojar, J. and Martínez, M.A. (2019). Intensity of singular stress field (ISSF) variation as a function of the Young's modulus in single lap adhesive joints. International Journal of Adhesion and Adhesives, 12(95), 102418. DOI: 10.1016/j.ijadhadh.2019.102418

[14] Liecht, K.M. and Chai., Y.S. (1992). Asymmetric Shielding in Interfacial Fracture Under In-Plane Shear, Journal of Applied Mechanics, 59, pp. 295-304. DOI:10.1115/1.2899520.

[15] Sun, C.T. and Jih, C.J. (1987). On Strain-Energy Release Rates for Interfacial Cracks in Bi-Material Media, Engineering Fracture Mechanics, 28(1), pp. 13-20. DOI: 10.1016/0013-7944(87)90115-9.

[16] Volinsky, A.A., Moody, N.R. and Gerberich W.W. (2002) Interfacial toughness measurements for thin films on substrates, Acta Materialia, 50, pp. 441-466. DOI: 10.1016/S1359-6454(01)00354-8.

[17] Hutchinson, J. and Suo, Z. (1991). Mixed Mode Cracking in Layered Materials, Advances in Applied Mechanics, 29, pp. 63-191. DOI: 10.1016/S0065-2156(08)70164-9.

[18] Sih GC (1974) Strain-energy-density factor applied to mixed mode crack problems. International Journal of Fracture, 10 (3), pp. 305-321. DOI: 10.1007/BF00035493.

[19] Lazzarin, P and Zambardi, R (2001) A finite-volume-energy based approach to predict the static and fatigue behavior of components with sharp V-shaped notches, International Journal of fracture, 112, pp. 275-298. DOI: 10.1023/A:1013595930617.

[20] Torabi, A.R. and Berto, F (2014) Strain energy density to assess mode II fracture in U-notched disk-type graphite plates, International Journal of Damage Mechanics, 23(7), pp. 917-930. DOI: 10.1177/1056789513519349.

[21] Arcan, M., Hashin, Z. and Voloshin, A. (1978) A Method to Produce Uniform Plane-stress States with Applications to Fiber-reinforced Materials, Experimental Mechanics, 18 (4), pp141-146.

[22] Voloshin, A. and Arcan, M. (1980). Failure of Unidirectional Fiber-reinforced Materials-- New Methodology and Results, Experimental Mechanics, 20 (5)- 41, pp. 280 - 284.

[23] Bresson, G., Jumel, J., Shanahan, M. E.R. and Serin, P. (2012). Strength of adhesively bonded joints under mixed axial and shear loading, International Journal of Adhesion \& Adhesives, 35, pp. 27-35. DOI: 10.1016/j.ijadhadh.2011.12.006.

[24] Abadi, R.H., Torun, A.R.,. Fard, A.M.Z and Choupani, N. (2020). Fracture characteristics of mixed-mode toughness of dissimilar adherends (cohesive and interfacial fracture), Journal of Adhesion Science and Technology, 34(6), pp. 599-615. DOI: 10.1080/01694243.2019.1674102.

[25] Badulescu, C., Cognard, J.Y., Creachcadec, R. and Vedrine, P. (2012). Analysis of the low temperature-dependent behaviour of a ductile adhesive under monotonic tensile/compression-shear loads, International Journal of Adhesion \& Adhesives, 36, pp. 56-64. DOI: 10.1016/j.ijadhadh.2012.03.009

[26] Créachcadec, R., Sohier, L., Cellard, C. and Gineste, B. (2015). A stress concentration-free bonded Arcan tensile compression shear test specimen for the evaluation of adhesive mechanical response, International Journal of Adhesion \& Adhesives, 61, pp. 81-92. DOI: 10.1016/j.ijadhadh.2015.05.003.

[27] Arnaud, N., Créachcadec, R. and Cognard. J.Y. (2014). A tension/compression-torsion test suited to analyze the mechanical behaviour of adhesives under non-proportional loadings, International Journal of Adhesion \& Adhesives 53, pp. 3-14. DOI: 10.1016/j.ijadhadh.2014.01.013.

[28] Cognard, J.Y., Créac'hcadec, R. (2009). Analysis of the Non-linear Behavior of an Adhesive in Bonded Assemblies Under Shear Loadings. Proposal of an Improved TAST, Journal of Adhesion Science and Technology, 23, pp.13331355. DOI: $10.1163 / 156856109 X 432956$

[29] Legendre, J., Créachcadec, R., Gilbert, F. and Jacquet, D. (2018). New method to measure the adhesion capability of metallic surface under shear loading using a modified Arcan test, The Journal of Adhesion, 94(12), pp. 1017-1035. DOI: $10.1080 / 00218464.2017 .1334557$.

[30] Sousa, F.C., Akhavan-Safar, A., Goyal, R., da Silva, L.F.M. (2020). The influence of mode mixity and adhesive system on the fatigue life of adhesive joints, Fatigue and Fracture of Engineering Materials and Structures., 43(10), pp. 23372348. DOI: $10.1111 /$ ffe.13301. 
[31] Suwanpakpraek, K., Patamaprohm, B., Phongphinittana, E., Chaikittiratana, A. (2020). Experimental Investigation and Finite Element Modelling of the Influence of Hydrostatic Pressure on Adhesive Joint Failure, IOP Conference Series: Materials Science and Engineering, 886(1), 012052. DOI: 10.1088/1757-899X/886/1/012052.

[32] Jouan, A. and Constantinescu, A. (2018). A critical comparison of shear tests for adhesive joints, International Journal of Adhesion and Adhesives, 84, pp. 63-79. DOI: 10.1016/j.ijadhadh.2018.02.035.

[33] Daniel, I.M., Ishai, O. (2006). Engineering mechanics of composite materials, 2nd ed. Oxford University Press.

[34] Hsieh, C.L. and Tuan, W.H. (2005). Poisson's ratio of two-phase composites, Materials Science and Engineering A, 396, pp. 202-205. DOI: 10.1016/j.msea.2005.01.029.

[35]Jia, Y., Peng, K., Gong, X.-l. and Zhang, Z. (2011). Creep and recovery of polypro-pylene/carbon nanotube composites, Int. J. Plast., 27, pp. 1239 - 1251. DOI: 10.1016/j.ijplas.2011.02.004.

[36] Bronz, A.V., Efremov, V.I., Plotnikov, A.D., Chernyavsky, A.G. (2014) Alloy 1570c -material for pressurized structures of advanced reusable vehicles of RSC, Energia, Kosmicheskaya Tekhnika i Tekhnologia, 4(7), pp. 62-67.

[37] L.F.M. da Silva, Rodrigues, T.N.S.S., Figueiredo, M.A.V., de Moura, M.F.S.F. and Chousal, J.A.G. (2006). Effect of Adhesive Type and Thickness on the Lap Shear Strength, The Journal of Adhesion, 82(11), pp. 1091-1115.

DOI: $10.1080 / 00218460600948511$

[38] Brewer, J.C. and Lagace, P.A. (1988). Quadratic Stress Criterion for Initiation of Delamination, Journal of Composite Materials, 22, pp. 1141-1155. DOI: 10.1177/002199838802201205

[39] Pestov, A.V., Osipova, V.A., Koryakova, O.V., Gorbunova, T.I., Smirnov, S.V. and Veretennikova. I.A. (2020). Preparation of a New Material Based on Epoxy Oligomers for Forming Corrosion-Protective Coatings, Russian Journal of Applied Chemistry, 93(3), pp. 391-396. DOI: 10.1134/S1070427220030118.

[40] Pestov, A.V., Puzyrev, I.S., Mekhaev, A.V., Gorbunova, T.I., Saloutin, V.I., Smirnov, S.V., Vichuzhanin, D.I. and Matafonov, P.P. (2014). Modification of Adhesive Materials Based on Epoxy Oligomers with Fluorinated Organic Compounds, Russian Journal of Applied Chemistry, 87(4), pp. 474-479. DOI: 10.1134/S10704272140400132. 